\title{
Design of Physical GaMes for LEARNINg THE LOTUS EFFECT
}

\author{
Wernhuar Tarng ${ }^{1}$, Shih-Hsien Tsai ${ }^{1}$, Chih Ming Lin ${ }^{2}$, \\ Chi-Young Lee ${ }^{3}$ and Hsin-Hun Liou ${ }^{4}$ \\ ${ }^{1}$ Graduate Institute of Computer Science, \\ National Hsinchu University of Education, Taiwan \\ ${ }^{2}$ Department of Applied Science, \\ National Hsinchu University of Education, Taiwan \\ ${ }^{3}$ Department of Materials Science and Engineering, \\ National Tsing Hua University, Taiwan \\ ${ }^{4}$ Department of Computer Science and Information Engineering, \\ National Central University, Taiwan \\ wtarng@mail.nhcue.edu.tw, bvbvjimmy@gmail.com, \\ cmlin@mail.nhcue.edu.tw, \\ cylee@mx.nthu.edu.tw, viviliu0501@gmail.com
}

\begin{abstract}
The lotus effect is a learning topic of nanoscience commonly seen in elementary schools. However, nanostructures cannot be observed with naked eyes or using general microscopes. Lacking interactive operating environments, it is not easy to inspire students to explore nanophenomena. This study used virtual reality (VR) technology to develop two physical games, namely "Water Drop in the Maze" and "Cleaning the Dust", to show the macroscopic and microscopic structures of lotus leaves respectively. Students can control the rolling direction of water drop by the 3-axis accelerometers in smart phones or tablet PCs to complete the missions, and observe the hydrophobic effect and self-cleaning effect of the lotus as well the as the scales of water drops, dust and the nanostructure on the surface of lotus leaves. A teaching experiment was conducted and the results showed the learning achievement of using physical games to learn the lotus effect was significantly higher than that of using instructional video. The questionnaire results also revealed that most students thought the physical games could enhance their motivation and interest in learning the lotus effect.
\end{abstract}

\section{KEYWORDS}

Nanotechnology, Lotus Effect, Virtual Reality, Physical Game, Situated Learning

\section{INTRODUCTION}

Feynman [1], the father of nanotechnology, mentioned "There's Plenty of Room at the Bottom" at a meeting of American Physical Society in 1959, and he predicted the development of technologies will move forward into a tiny level. These were the words of wisdom in nanotechnology and they had gradually become well known in 1990. In the last two decades, the advanced countries fully supported the research and development of nanotechnology, and it is the new hope of economy in the 21 st century. Nanotechnology changes the industrial structure and human lifestyle, and is therefore considered as the fourth industrial revolution. Some people even predict that its impact on human life is greater than that of information technology or semiconductor industry.

DOI : $10.5121 /$ ijcsit.2012.4604 
Considering the importance of nanotechnology, National Science Council (NSC), Taiwan began to promote the National Nanoscience and Nanotechnology Program (NNNP) in 2002, and it was aimed to establish a nanotechnology personnel training mechanism for the promotion and development of nanotechnology industry. In order to foster the nanotechnology personnel at all levels, NSC proposed the National Nanoscience Training Project (NNTP) to promote K12 nanotechnology and nanoscience education. The goal was to reinforce the people's literacy of nanotechnology from school teachers and students to the general public, thus contributing to the popularization of nanotechnology education.

The topics of nanotechnology can often be found in K12 science and technology curriculum. Nanostructures cannot be observed with naked eyes or using general microscopes, so teachers usually use pictures and video to explain nanophenomena after teaching and observation activities. For example, a teacher may spray water on the leaves of Alocasia macrorrhiza and taro and ask students to distinguish between these two plants by observing the rolling of water drops on both plants. However, students obtain knowledge passively due to the lack of practice in the microscopic environment, so it is not easy to inspire their interest and motivation in exploring the principles of nanophenomena. The objective of this study is to design teaching materials for learning the lotus effect to enhance students' learning interest and motivation by using interactive physical games.

Virtual reality (VR) is a technology to create an interactive environment to simulate the real world through our sense organs. We can see, hear, and even feel in the created scenes as if situated in the real world, and even interact with the objects in the virtual scenes. The most commonly used technique in virtual reality is $3 \mathrm{D}$ visual simulation, allowing users to interact with virtual situations by using stereo glasses or head-mounted display (HMD) to enhance their initiative, operability and sensitivity [2]. Moreover, using VR to enrich a learner's experiences has been the focus of many researchers [3]. It was believed that the application of VR in learning can enhance students' interest and motivation [4] [5] and help develop their ability and positive attitudes toward learning [6].

Game-based learning is considered as an efficient way to inspire learners' motivation. Instructional designers may convert teaching materials into interactive games, not only allowing students to increase the sense of accomplishment in the problem-solving process, but also enhancing their interest in learning [7]. As the advance of information and communication technology, digital game-based learning has become the mainstream of learning technologies. The attractive learning contents in digital games enable students to immerse themselves into the games and experience different roles and ideas [8]. This study designed two physical games based on the lotus effect. Students can physically interact with the teaching materials to understand the lotus effect and its principles when playing the games, which can also inspire their learning interest and motivation.

Situated Learning was first proposed by Brown et al. [9] and its concept is to simulate a realistic environment to provide learners with learning situations for exploring knowledge by the interaction with real or virtual teaching materials. Situated learning emphasizes the reality of learning activities, and its viewpoint is similar to Dewey's theory "Learning by Doing" [10] and Kolb's theory "Learning from Experiences" [11]. Obtaining knowledge through the operation of physical games can help transform the concepts into images or symbolic representation for the interpretation of external environments by thinking in an abstract or logical way. In that case, learners can easily understand and will not forget quickly. Therefore, physical games can enhance learning effectiveness and produce learning transference for applications in similar situations in the future. 
The structure and properties of a substance in the nano world are very different from those in the macro environment. For example, the surface of a lotus leaf is clean even if it is grown out of mud, and butterfly wings have brilliant colours when waving or observed from different angles. These phenomena are due to the nanostructure on the seemingly smooth surface, but it is not an easy thing for children to understand the principles of nanophenomena by the observation with naked eyes. In learning the lotus effect, students often encounter the following problems. For example, they cannot obtain lotus leaves for observing the lotus effect if there is not a lotus pond in their campus. Besides, the electron microscope is rarely used in $\mathrm{K} 12$ science teaching because it is expensive and easily damaged by improper operation.

To solve the problems in teaching nanoscience, this study used VR technology to develop two physical games for learning the lotus effect, allowing students to operate in the macroscopic and microscopic environments to enhance their learning interest and motivation. In this way, outdoor teaching activities or electron microscopes are not required in teaching nanoscience because the physical games can make learning the principles of the lotus effect more convenient. In addition, the theoretical explanation for the concepts of nano scale and nanostructure after the games enables students to better understand the lotus effect.

\section{SYSTEM DESIGN AND OPERATION}

In this study, the development environment of physical games is Windows OS and the design tools are Shiva3D and 3ds Max. After the completion of system development, ShiVa3D's Authoring Tool was used to convert the installation file (.apk) and then it was published to the Android Market for users to download. The system can be executed on smart phones or tablet PCs, and it mainly includes two physical games, namely "Water Drop in the Maze" and "Cleaning the Dust", to present the macroscopic and microscopic structures on the surface of lotus leaves respectively. Students can control the rolling direction of a water drop by the function of 3-axis accelerometers in smart phones or tablet PCs to complete the missions, and observe the hydrophobic effect and self-cleaning effect of the lotus as well the as the scales of water drops, dust and the nanostructure of lotus leaves.

\subsection{System Design}

The system modules include: camera control, time control, interface control, collision detection, 3 -axis accelerometer, a lotus pond, 2 physical games, a quiz section, a database, and the related API programs. Some of the modules are introduced in the following, and the remaining functions will be described in the next section.

\section{- Camera control}

Camera control is an integral part in VR design because it determines the viewing direction of users in the 3D scene. The viewing angle can be switched between the first-person view and the third-person view by camera control functions for the user to participate in interactive processes. Shiva3D provides many camera control functions to cooperate with rotate( ) and translate( ) functions such that the camera can move flexibly to provide the required visual effects.

- Time control

Shiva3D has no delay functions such as Sleep( ), and it doesn't support direct access to the data of current time in the format of hour, minute and second either. However, Shiva3D provides the API programs to obtain current year, month and the total seconds passed in one day, which can be converted into current time. Therefore, the function of Sleep( ) can be achieved by reading the 
value of total seconds twice for subtraction and combining conditional expressions for the control of switching between different scenes. It can also be used to design the countdown timer in a game round.

- Interface control

Shiva3D provides a number of functions for the user interface design, e.g., Label, Button, List, and Drop-down Menu, and they can be used to make the game design more convenient. This study created several touch buttons such as Enter (the system), Exit (the system), Switch (between two different pages), and Play (the game) to change the user interface and increase operational fluency.

- Collision detection

Shiva3D provides some collision API settings and dynamic functions to make the program design more convenient. In the physical games, the settings of dynamic functions enable the water drop to roll on the curved surface of the lotus leaf, and the settings of collision detection produce the rebounding effect when the water drop is rolling in the maze. It can also be used to detect if the water drop collides with and absorbs a small piece of dust, or reach the destination of the maze to complete the mission. In the scene of lotus pond, it can be used to detect if the water drops fall to the ground and disappear in the pond to prevent the system from running out of memory.

\section{- 3-axis accelerometer}

The accelerometer, also known as the gravitational acceleration sensor, can be used to measure the movement of a device itself. Like the gyroscope, it is often used in an inertial guidance system. For example, the airbag system of a vehicle can use it to detect a collision if the vehicle decelerates suddenly. When applied in a mobile device, it can be used to design the motion sensing user interface. When applied in video games and toys, the operation of joysticks can be replaced by motion control to increase personal experience and physical interaction. This study used the built-in API programs of Shiva3D to obtain the acceleration values of a mobile device and convert them into the orientation and acceleration data of the water drop. Users can change the rolling direction of the water drop by inclining the mobile device to reach the destination when playing the physical games.

\section{- Database}

The database can be used for system login validation and recording the learning process. After login, the system will download personal data and store them as variables for use by the scenes. It can also upload data to the database through server-side PHP programs.

\subsection{System Operation}

At first, the system will show the login page, and the user has to enter the correct ID and password to login. After that, a question about the lotus effect is displayed on the screen, guiding the user to enter a lotus pond. Meanwhile, it is raining in the scene and the raindrops fall down to the lotus leaves, providing the scenario of playing the physical games to learn the lotus effect. Namely, the games of "Water Drop in the Maze" and "Cleaning the Dust" were designed to show the hydrophobic effect and self-cleaning effect respectively. The system will introduce some basic concepts about the lotus effect before starting the games, and the user can click the Play button to play the game after reading the information. There is also a quiz section at the end of each game to see if the user has learned the related concepts about the lotus effect. If the answer 
is incorrect, the system will ask the user to try again; otherwise, the system will explain the principle about the answer. The operating procedure of the system (Figure 1) is described as follows.

\section{- Lotus pond}

After login, the system will show the question "Why water drops can roll on the surface of lotus leaves and take away dust?" (Figure 2), directing the user to the learning topic of lotus effect. After that, the system will enter the scene of a lotus pond (Figure 3), where the user can pick a lotus leaf for observing the lotus effect. Then, the focus is getting closer to the lotus leaf and enters the macro view of the lotus (Figure 4).

- Macro view of the lotus

At the beginning, a water drop falls from the sky and drips down to the lotus leaf. The user may incline the mobile phone or tablet PC to control the rolling direction of the water drop on the lotus leaf and become familiar with the lotus effect. The user can click the Enter button to enter the game "Water Drop in the Maze". The system will first introduce the basic concepts about the lotus effect, and then the user can play the game by clicking the GO button after reading the related information on this page.
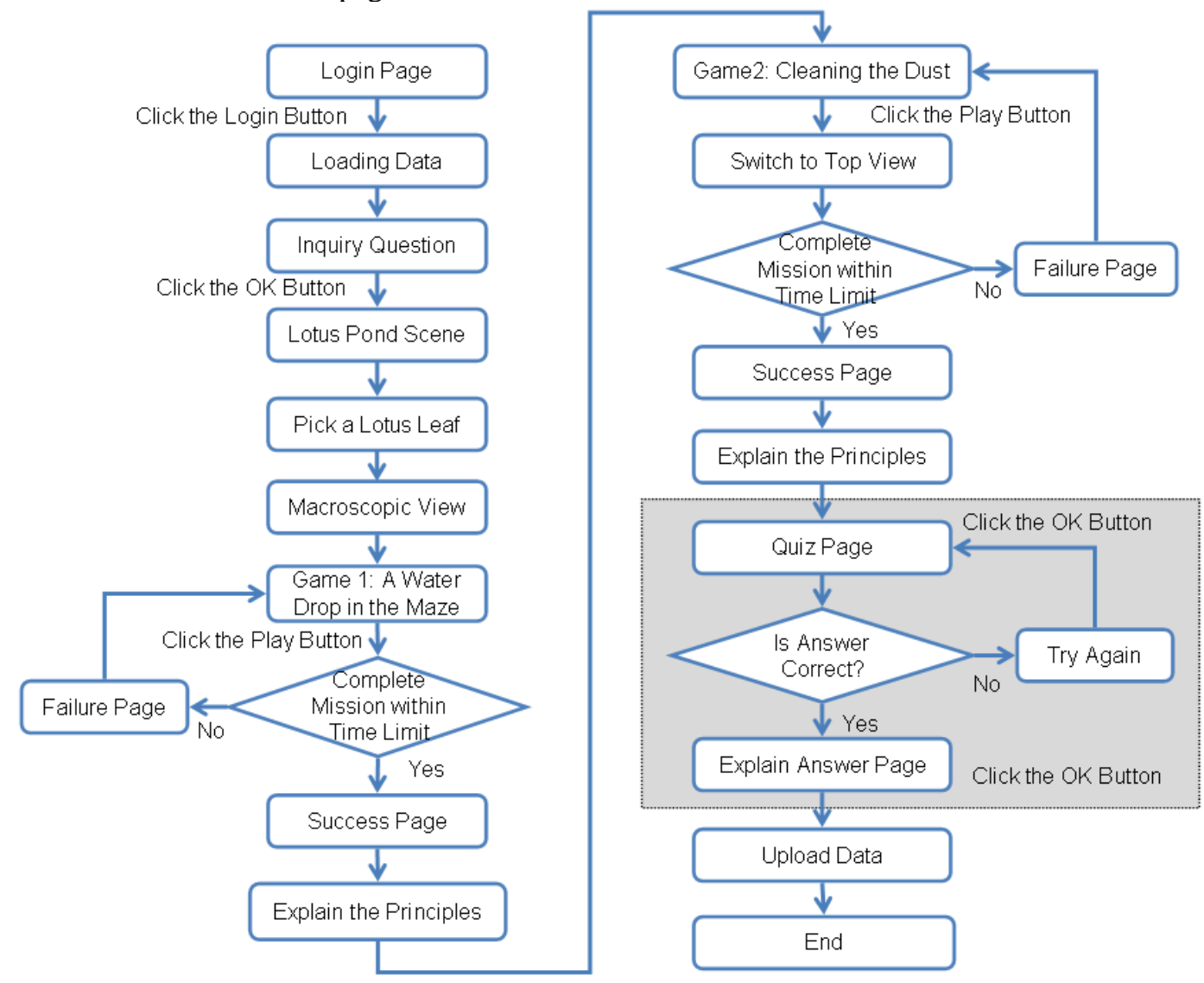

Figure 1. The operating procedure of the system 


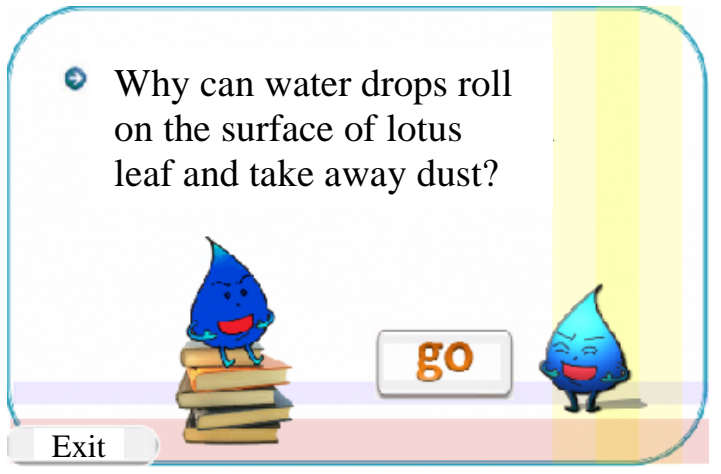

Figure 2. The question before starting the game.

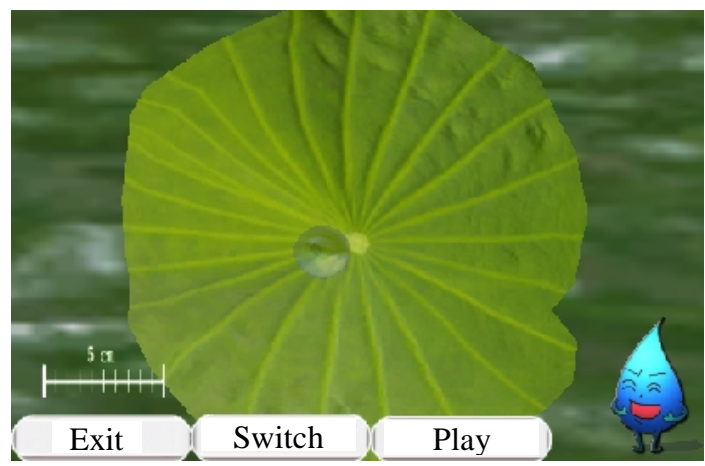

Figure 4. A water drop on the lotus leaf

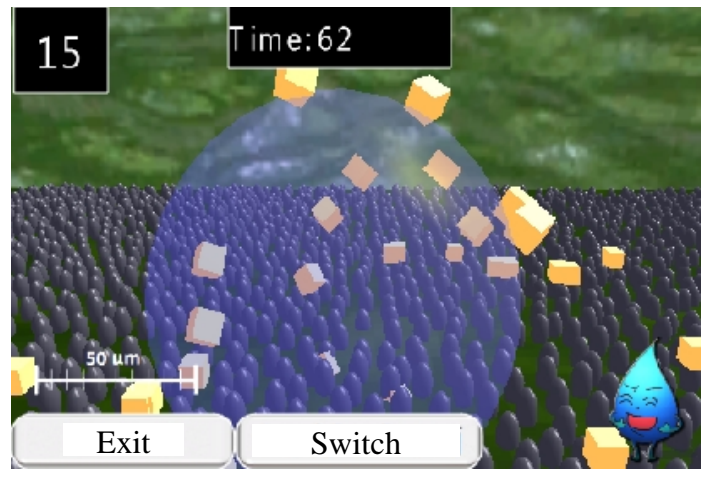

Figure 6. Playing "Cleaning the Dust"

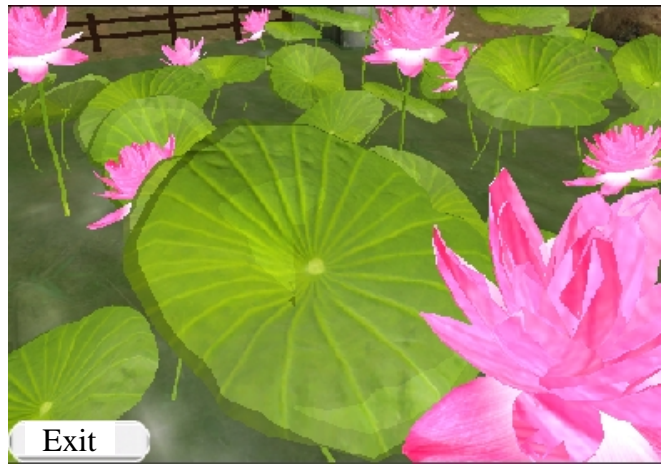

Figure 3. The scene of a virtual lotus pond

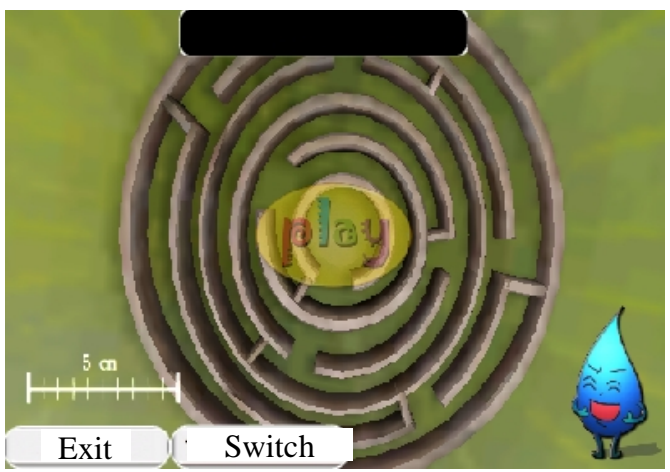

Figure 5. Playing "Water Drop in the Maze"

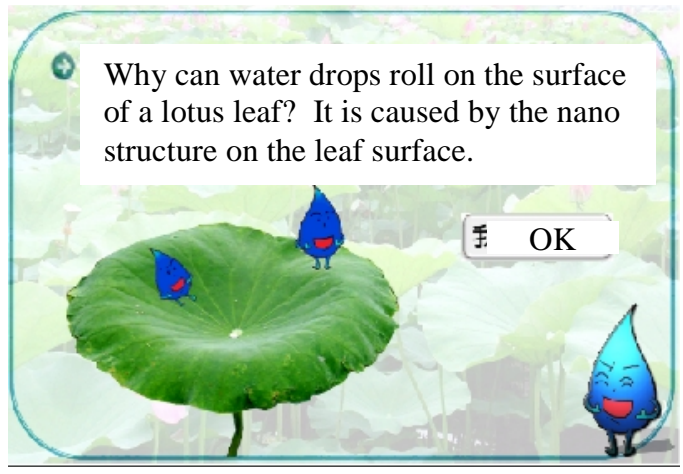

Figure 7. Explaining principles of lotus effect

- Game 1: Water Drop in the Maze

The user can click the Play button to enter the physical game "Water Drop in the Maze" (Figure 5 ), and incline the mobile device to roll the water drop to the maze destination within the time limit. The system will show the success page (or the failure page) if the user completes the mission (or can't make it). The game was designed as a repetitive round, so the user has to restart the game if he or she cannot reach the destination before the time runs out. 
- Game 2: Cleaning the Dust

The user can click the Play button to start the physical game "Cleaning the Dust" (Figure 6), and roll the water drop to run over and absorb every piece of dust on the lotus leaf within the time limit. The system will show the success page (or the failure page with the remaining number of dust) if the user completes the mission (or can't make it). The user has to restart the game if he or she fails the mission.

- Explaining the lotus effect

The system will explain the principles and related concepts of lotus effect after the physical games, i.e., the principle of hydrophobic effect for "Water Drop in the Maze" and that of selfcleaning effect for "Cleaning the Dust". The user can click the Go button to move to the next page after reading the information on this page.

\section{- Answering the questions}

After entering the quiz section (Figure 7), the user can select an answer from the options of the question about the principles of the lotus effect. If the answer is incorrect, the system will display an error message and provide some hints for the user to try again. If the answer is correct, the system will explain in more details and then move to the next question.

\section{TEACHING EXPERIMENT}

In this study, a teaching experiment was conducted to investigate if the applications of physical games in teaching the lotus effect can enhance students' learning achievement. The research tools shown in Table 1, including an achievement test, a questionnaire survey, observation and interviews, were used to produce the quantitative and qualitative results. The objective is to see if there is a significant difference in students' learning effectiveness by using different assistant tools (physical games or instructional video) and students' attitudes and experiences after using the physical games for learning. The experimental design, learning effectiveness, questionnaire results, and observation findings are described in the following.

Table 1. Research problems, research tools and results

\begin{tabular}{|c|c|c|}
\hline Research Problems & Research Tools & Results \\
\hline $\begin{array}{l}\text { 1. Is there a significant difference in students' } \\
\text { learning effectiveness by using different assistant } \\
\text { tools (physical games or instructional video)? }\end{array}$ & Achievement Test & $\begin{array}{l}\text { Quantitative } \\
\text { Analysis }\end{array}$ \\
\hline $\begin{array}{l}\text { 2. What are the attitudes and experiences of students } \\
\text { after using the physical games for learning? }\end{array}$ & $\begin{array}{l}\text { Questionnaire } \\
\text { Survey }\end{array}$ & $\begin{array}{l}\text { Quantitative } \\
\text { Analysis }\end{array}$ \\
\hline $\begin{array}{l}\text { 3. What are the findings after applying the physical } \\
\text { games in teaching the lotus effect? }\end{array}$ & $\begin{array}{l}\text { Observation and } \\
\text { Interviews }\end{array}$ & $\begin{array}{l}\text { Qualitative } \\
\text { Analysis }\end{array}$ \\
\hline
\end{tabular}

\subsection{Experimental Design}

This study selected two 5th grade classes (each containing 27 students) from an elementary school at Taichung as experimental samples, one as the control group and the other as the experimental group. The non-equivalent control group pretest-posttest design was used to explore if applying physical games in teaching the lotus effect could enhance students' learning motivation and achievement. The learning contents included the principles of lotus effect and the 
basic concepts in nanoscience. In the classes, the experimental group used the physical games developed in this study to assist teaching while the control group used the instructional video produced by National Science and Technology Museum, Kaohsiung [12] as the teaching aids. The learning contents of lotus effect belong to the field of Natural Science and Life Technology in Grade 1-9 Curriculum. The questions of achievement test were designed based on the learning contents and background knowledge of students, and then modified and verified by experts in the related fields. The time allocation for the teaching experiment is shown in Figure 8. The variables in the teaching experiment are described in the following:

- Independent variable: In this study, students were divided into the control group and experimental group. The control group used instructional video while the experimental group used physical games for learning the lotus effect. Therefore, the teaching tool is the independent variable.

- Covariate: The pretest score was used as the covariate and analyzed by the independent sample t-test to verify whether the background knowledge of the control group and experimental group before the teaching experiment was equivalent.

- Dependent variable: The posttest score was used as the dependent variable and analyzed by an ANCOVA to see if a significant difference in learning effectiveness existed between the control group and experimental group.

- Control variables: To prevent the interference by other factors from influencing the experimental results, the teacher, teaching hours and learning contents were set as control variables. In that case, both groups were taught by the same teacher for the same time (a total of 80 minutes in two classes) using the same learning contents.

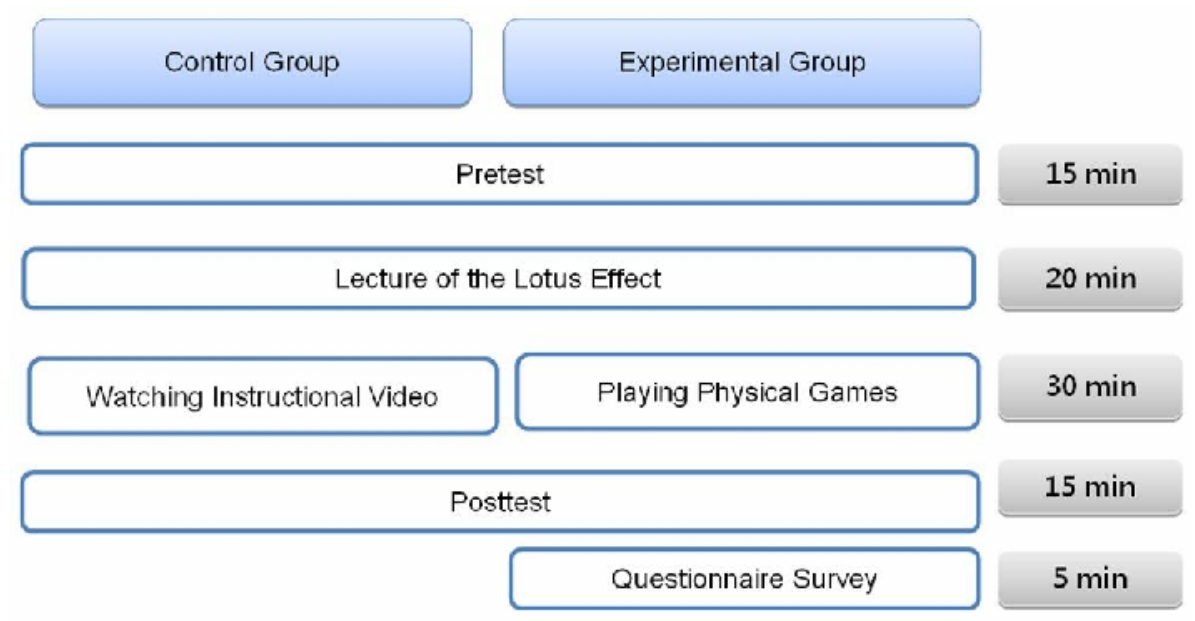

Figure 8. The time allocation for the teaching experiment

\subsection{Learning Effectiveness}

This study used an independent samples t-test to analyze if the background knowledge of the control group and experimental group before the teaching experiment was about the same. The average pretest and posttest scores were calculated to analyze the progress made by the two groups after the teaching experiment. An analysis of covariance (ANCOVA) was performed to see if there was a significant difference in learning effectiveness between the two groups. 


\section{- Homogeneity test}

In this study, the independent samples t-test was used to analyze the pretest scores of the control group and experimental group (as shown in Table 2) to see if there was a significant difference between the two groups in their background knowledge. No significant difference was found by the test, meaning the two groups had about the same background knowledge.

Table 2 Statistics of pretest scores by the two groups

\begin{tabular}{|c|c|c|c|c|}
\hline Group & $\begin{array}{c}\text { Number of } \\
\text { Students }\end{array}$ & $\begin{array}{c}\text { Average } \\
\text { Score }\end{array}$ & $\begin{array}{c}\text { Standard } \\
\text { Deviation }\end{array}$ & $\begin{array}{c}\text { Standard } \\
\text { Error }\end{array}$ \\
\hline Control Group & 27 & 38.89 & 15.92 & 3.06 \\
\hline Experimental Group & 27 & 39.12 & 15.45 & 2.98 \\
\hline
\end{tabular}

The assumption of variance homogeneity must be satisfied before the independent samples t-test is conducted. Therefore, this study used Levene's test to exam the pretest scores of the two groups first and its results show that $\mathrm{f}=0.2$ and $\mathrm{p}=0.0656(>0.05)$, so the assumptions of variance homogeneity is satisfied. The results of independent samples t-test show that $t=-0.054$ and $\mathrm{p}=0.957(>0.05)$, indicating there is no significant difference between the pretest scores of the control group and experimental group. In other words, the background knowledge of the two groups is about the same.

\section{- Statistics of pretest and posttest scores}

The statistics of pretest and posttest scores for the control group and experimental group are shown in Table 3. For the control group, the average pretest score is 38.89 and the average posttest scores is 65.51 . Therefore, the average progress is 26.62 . For the experimental group, the average pretest score is 39.12 and the average posttest scores is 76.85 . Thus, the average progress is 37.73 .

Table 3. Statistics of pretest and posttest scores for both groups

\begin{tabular}{|c|c|c|c|c|}
\hline Group & Achievement Test & $\begin{array}{c}\text { Number of } \\
\text { Students }\end{array}$ & Average Score & $\begin{array}{c}\text { Standard } \\
\text { Deviation }\end{array}$ \\
\hline \multirow{2}{*}{ Control group } & Pretest & 27 & 38.89 & 15.92 \\
\cline { 2 - 5 } & Posttest & 27 & 65.51 & 19.49 \\
\hline \multirow{2}{*}{ Experimental Group } & Pretest & 27 & 39.12 & 15.46 \\
\cline { 2 - 5 } & Posttest & 27 & 76.85 & 13.41 \\
\hline
\end{tabular}

This study used a paired samples t-test to analyze the pretest and posttest scores for the two groups and the results are shown in Table 4. The results of control group show that $t=-9.50$ $(<0.05)$, indicating using instructional video to assist teaching can achieve significant improvement in learning achievement. The results of experimental group show that $t=-12.53$ $(<0.05)$, indicating using physical games to assist teaching can also enhance the learning achievement significantly.

Table 4. Statistics of paired samples T-test for both groups

\begin{tabular}{|c|c|c|c|c|c|}
\hline Pretest- Posttest & Average & $\begin{array}{c}\text { Standard } \\
\text { Deviation }\end{array}$ & $\mathrm{T}$ & $\begin{array}{c}\text { Degrees of } \\
\text { Freedom }\end{array}$ & Significance \\
\hline Control Group & -26.62 & 14.56 & -9.50 & 26 & $0.000^{*}$ \\
\hline Experimental Group & -37.73 & 15.64 & -12.53 & 26 & $0.000^{*}$ \\
\hline
\end{tabular}




\section{- ANCOVA analysis}

In this study, an ANCOVA is performed to analyze if there is a significant difference in learning effectiveness between the control group and experimental group. The assumptions of variance homogeneity and homogeneity of regression coefficients must be satisfied before using the ANCOVA. This study used Levene's test to analyze the variance homogeneity for the samples, and the results show that $\mathrm{f}=1.08$ and the significance $\mathrm{p}=0.695(>0.05)$, indicating the two groups are homogeneous. The results of homogeneity of regression coefficient show that $\mathrm{f}=3.8$ and the significance $\mathrm{p}=0.057(>0.05)$, indicating the relationship of the covariate (pretest score) and the dependent variable (posttest scores) is not affected by the independent variable (teaching tool), satisfying the assumption of homogeneity of regression coefficient and thus can be analyzed by the ANCOVA (table 5).

Table 5. ANCOVA results of learning achievement for both groups

\begin{tabular}{|c|c|c|c|c|c|}
\hline Source & Sum of Squares & $\begin{array}{c}\text { Degrees of } \\
\text { Freedom }\end{array}$ & Mean Square & $\mathrm{F}$ & Significance \\
\hline Groups & 1694.18 & 1 & 1694.18 & 8.75 & $0.005^{*}$ \\
\hline Error & 9872.94 & 51 & 193.59 & & \\
\hline
\end{tabular}

After excluding the impacts by covariate and dependent variables, the ANCOVA results show that $\mathrm{f}=8.752$ and $\mathrm{p}=0.005(<0.05)$, indicating there is a significant difference in the learning effectiveness between the control group and experimental group and the learning effectiveness of the experimental group is significantly higher than that of the control group. More precisely, using the physical games in learning the lotus effect can achieve better learning effectiveness than using instructional video.

\subsection{Questionnaire Survey}

A questionnaire survey was conducted to investigate students' attitudes about the features and effectiveness of the physical games. The questionnaire adopted a five-point scale [13] (strongly agree: 5 , agree: 4 , no comment: 3 , disagree: 2 , and strongly disagree: 1 point). It contained a total of 15 questions in 3 categories, interface design, multimedia features, and practicability \& effectiveness, and the overall reliability $\alpha$ value is 0.914 , showing this questionnaire is reliable. The percentage of each option and the average score for every question are shown in the following (Table 6) for the analysis of students' attitudes after using the physical games for learning the lotus effect. 
International Journal of Computer Science \& Information Technology (IJCSIT) Vol 4, No 6, December 2012

Table 6. The cumulative statistics of questionnaire survey

\begin{tabular}{|c|c|c|c|c|c|c|c|}
\hline & Item & $\begin{array}{l}\text { Strongly } \\
\text { Agree }\end{array}$ & Agree & $\begin{array}{c}\text { No } \\
\text { Comment }\end{array}$ & Disagree & $\begin{array}{l}\text { Strongly } \\
\text { Disagree }\end{array}$ & Average \\
\hline \multirow{5}{*}{ 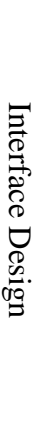 } & $\begin{array}{l}\text { 1. The system is easy to } \\
\text { use. }\end{array}$ & $85.2 \%$ & $7.4 \%$ & $7.4 \%$ & $0.0 \%$ & $0.0 \%$ & 4.78 \\
\hline & $\begin{array}{l}\text { 2. The system is } \\
\text { interesting. }\end{array}$ & $85.2 \%$ & $7.4 \%$ & $7.4 \%$ & $0.0 \%$ & $0.0 \%$ & 4.78 \\
\hline & $\begin{array}{l}\text { 3. The text is clear and the } \\
\text { font sizes are proper. }\end{array}$ & $92.6 \%$ & $3.7 \%$ & $3.7 \%$ & $0.0 \%$ & $0.0 \%$ & 4.89 \\
\hline & $\begin{array}{l}\text { 4. This system allows me to } \\
\text { learn more about the } \\
\text { lotus effect. }\end{array}$ & $85.2 \%$ & $7.4 \%$ & $7.4 \%$ & $0.0 \%$ & $0.0 \%$ & 4.78 \\
\hline & $\begin{array}{l}\text { 5. The execution speed is } \\
\text { fine. }\end{array}$ & $85.2 \%$ & $7.4 \%$ & $3.7 \%$ & $3.7 \%$ & $0.0 \%$ & 4.74 \\
\hline \multirow{5}{*}{ 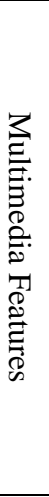 } & $\begin{array}{l}\text { 1. The system can show the } \\
\text { nanostructure clearly. }\end{array}$ & $85.2 \%$ & $7.4 \%$ & $7.4 \%$ & $0.0 \%$ & $0.0 \%$ & 4.78 \\
\hline & 2. The system is realistic. & $85.2 \%$ & $7.4 \%$ & $3.7 \%$ & $3.7 \%$ & $0.0 \%$ & 4.74 \\
\hline & $\begin{array}{l}\text { 3. The system provides } \\
\text { clear pictures and } 3 \mathrm{D} \\
\text { models. }\end{array}$ & $92.6 \%$ & $3.7 \%$ & $3.7 \%$ & $0.0 \%$ & $0.0 \%$ & 4.89 \\
\hline & $\begin{array}{l}\text { 4. I am interested in } \\
\text { learning the lotus effect } \\
\text { by using the system. }\end{array}$ & $88.9 \%$ & $3.7 \%$ & $3.7 \%$ & $0.0 \%$ & $3.7 \%$ & 4.74 \\
\hline & $\begin{array}{l}\text { 5. The 3D models allow me } \\
\text { to understand the } \\
\text { nanostructure of the lotus } \\
\text { leaves. }\end{array}$ & $85.2 \%$ & $11.1 \%$ & $3.7 \%$ & $0.0 \%$ & $0.0 \%$ & 4.81 \\
\hline \multirow{5}{*}{ 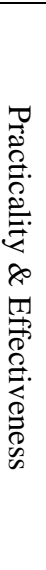 } & $\begin{array}{l}\text { 1. The system helps me } \\
\text { understand the concepts } \\
\text { of nanoscience. }\end{array}$ & $85.2 \%$ & $7.4 \%$ & $7.4 \%$ & $0.0 \%$ & $0.0 \%$ & 4.78 \\
\hline & $\begin{array}{l}\text { 2. The system helps me } \\
\text { understand the lotus } \\
\text { effect. }\end{array}$ & $88.9 \%$ & $3.7 \%$ & $7.4 \%$ & $0.0 \%$ & $0.0 \%$ & 4.81 \\
\hline & $\begin{array}{l}\text { 3. The system makes me } \\
\text { feel like to learn about } \\
\text { nanoscience. }\end{array}$ & $92.6 \%$ & $3.7 \%$ & $0.0 \%$ & $0.0 \%$ & $3.7 \%$ & 4.81 \\
\hline & $\begin{array}{l}\text { 4. The system helps me a } \\
\text { lot in learning } \\
\text { nanoscience. }\end{array}$ & $96.3 \%$ & $0.0 \%$ & $3.7 \%$ & $0.0 \%$ & $0.0 \%$ & 4.93 \\
\hline & $\begin{array}{l}\text { 5. I will continue using the } \\
\text { system in the future for } \\
\text { learning. }\end{array}$ & $85.2 \%$ & $3.7 \%$ & $7.4 \%$ & $3.7 \%$ & $0.0 \%$ & 4.70 \\
\hline
\end{tabular}

\section{- Interface design}

The average was 4.78 when asking students if the system was interesting and easy to use and allowed them to learn more about the lotus effect. Most students agreed the text was clear and the font sizes were proper (average=4.89), and they thought the execution speed of the system was fine (average=4.74). Generally speaking, most students gave a high rating for the interface and design; they thought the system was interesting and could help them learn the lotus effect. 
The averages were very high when students were asked if the system provided clear pictures and $3 \mathrm{D}$ models (average $=4.89$ ) to show the nanostructure clearly (average $=4.78$ ) and to help them understand the nanostructure of lotus leaves (average $=4.81$ ). The average was 4.74 when students were asked if the system was realistic and motivated them in learning. In general, most students had positive attitudes toward the multimedia features of the system, and they thought the lotus model was clear and could help them understand the nanostructure of the lotus.

- Practicality and effectiveness

Most students agreed that the system helped them a lot in learning science (average $=4.93$ ), more precisely, understanding the basic concepts of nanoscience (average $=4.78$ ) and the lotus effect (average $=4.81$ ). They would like to learn more knowledge in nanoscience (average $=4.81$ ) and continue using the system for learning (average $=4.70$ ). Hence, most students thought the system was helpful in learning the lotus effect and nanoscience, and they would like to use the system for learning in the future.

\subsection{Observation and Interviews}

The teaching experiment was conducted in an ordinary classroom. In order to decrease possible abnormalities, the researchers checked carefully to ensure the system was executed correctly on each tablet PC and connected to the wireless network at normal speed. Three teaching assistants stood by on the site to ensure all students could log in to the system to use the physical games. At the beginning, the researchers explained the system functions and operating procedure to the students and then let them operate freely. Students could raise questions when encountering any problems during operation.

In the classes, the researchers found that students were not interested in the PowerPoint contents; however, using multimedia as teaching tools could attract their attention and interest. Most students were focused on learning and responded quickly when watching video in the control group and playing physical games in the experimental group. During the learning process, the control group students were very interested in watching the video although they were not familiar with nanophenomena and the principles. They would discuss with each other and gave some feedback when they saw interesting pictures. Overall, the use of instructional video resulted in good learning effectiveness since it provided the related knowledge about the lotus effect and attracted students' attention in learning.

The experimental group students were interested in playing physical games to learn the lotus effect, and they operated by following the voice prompts to obtain the knowledge about lotus effect. Students had good skills in operating Tablet PCs; they would help each other when encountering problem, and raise questions to ask for help if necessary. The students had the habit of posting their idea on blogs, which revealed they were interested in learning the lotus effect by using physical games. They wished other courses could also have similar systems to assist learning. The learning process was recorded and uploaded to the database by the system, and the recorded data showed that most students studied the learning contents carefully by following voice prompts of the system. Besides, those students who answered more questions correctly usually had higher scores in the posttest than the other students did. However, students operated at different speeds in the learning process, so the voice prompts on mobile devices may interfere with each other in the classroom. In the future, it is suggested to let students wear headphones to avoid mutual interference in teaching applications. 


\section{Conclusions ANd Future Works}

In this study, the VR technology was used to develop two physical games "Water Drop in the Maze" and "Cleaning the Dust" to show the macroscopic and microscopic structures of the lotus. The user can control the rolling direction of the water drop via the 3-axis accelerometer of smart phones or tablet PCs to complete the missions, and observe the hydrophobic effect and selfcleaning effect of the lotus as well the as the scales of water drops, dust and the nanostructure on the surface of lotus leaves. A teaching experiment was conducted to investigate the learning effectiveness by using the physical games; a questionnaire survey was performed to analyze the attitudes of students after using the system. The ANCOVA results showed that the learning effectiveness of using physical games to learn the lotus effect was significantly higher than that of using instructional video; the questionnaire results showed that most students agreed that the physical games could enhance their motivation and interest in learning the lotus effect; they thought the system was interesting and could help them learn the lotus effect; In addition, the lotus model was clear and could help them understand the nanostructure of the lotus. Therefore, they would like to use the system for learning in the future.

This study used VR technology to develop physical games for learning the lotus effect. In the future, the augmented reality (AR) may be added to enable more physical interaction with the learning situation and the sense of immersion. The system in this study is focused on learning the lotus effect only, and it can be extended to include more teaching materials for learning the concepts of nanophenomena, like the butterfly effect and biological compass, and become an integrated learning system. In that case, students can learn the knowledge of nanoscience and its applications with more interest and motivation. Currently, students can only interact with the system due to the lacking of cooperation with peers. The elements of group competition and peer cooperation will be added in the future to enhance interaction among students.

\section{ACKNOWLEDGEMENT}

The authors wish to thank for the financial support of the National Science Council of the Republic of China under the contract number NSC 101-2120-S-007-002

\section{REFERENCES}

[1] Feynman, R. P. (1960). There's plenty of room at the bottom. Caltech Engineering and Science, 23, 5.

[2] Heim, M. (1993). The metaphysics of virtual reality. New York: Oxford University Press.

[3] Xiao, D. Y. (2000). Experiencing the library in a panorama virtual reality environment. Library Hi Tech, 18(2), 177-184.

[4] Auld, L. W. S. \& Pantelidis, V. S. (1994). Exploring virtual reality for classroom use: the virtual reality and education lab at East Carolina University. TechTrends, 39(1), 29-31.

[5] Winn, W. \& Bricken, W. (1992). Designing virtual worlds for use in mathematics education: the example of experiential algebra (Vol. 32).

[6] Ferrington, G. \& Loge, K. (1992). Virtual reality: A new learning environment. Computing Teacher, 19(7), 16-19.

[7] Hong, J. C. \& Liu, M. C. (1997). The design principles and applications of computer assisted learning. Taiwan Normal University Bookstore.

[8] Gee, J. P. (2003). What video games have to teach us about learning and literacy? ACM Computers in Entertainment, 1(1), 1-4.

[9] Brown, J. S., Collins, A. \& Duguid, P. (1989). Situated cognition and the culture of learning. Educational Researcher, 18(1), 32-42.

[10] Dewey, J. (1938). Theories of education. New York: Macmillan.

[11] Kolb, D. A. (1984). Experiential learning: experience as the source of learning and development. Englewood Cliffs, NJ: Prentice-Hall.

[12] National Science and Technology Museum (2008). A new world in nanotechnology, http://nano.nstm.gov.tw/01conception/conception02_03.asp.

[13] Likert, R. (1932). A technique for the measurement of attitudes. Archives of Psychology, 22(140), 1-55. 